\title{
Human amniotic mesenchymal stem cells alleviate lung injury induced by ischemia and reperfusion after cardiopulmonary bypass in dogs
}

\author{
Yong Qiang ${ }^{1}$, Guiyou Liang ${ }^{2}$ and Limei $\mathrm{Yu}^{3}$
}

Transplantation of mesenchymal stem cells may inhibit pathological immune processes contributing to ischemia/ reperfusion (I/R) injury. This study aimed to assess the capacity of human amniotic MSC (hAMSCs) to ameliorate I/R injury in a dog model of cardiopulmonary bypass (CPB). Dissociated hAMSCs were cultured ex vivo, and their immunophenotypes were assessed by flow cytometry and immunohistochemistry. A dog model of CPB was established by surgical blockage of the aorta for $1 \mathrm{~h}$. Dogs either underwent mock surgery (Sham group), CPB (model group), or CPB, followed by femoral injection of $2 \times 10^{7} \mathrm{hAMSCs}(n=6)$. Anti-human nuclei staining revealed hAMSCs in the lungs $3 \mathrm{~h}$ after surgery. Oxygen index (OI) and respiratory index (RI) of arterial blood were measured using a biochemical analyzer.

Venous blood TNF- $a$, IL-8, MMP-9, and IL-10 concentrations were measured by ELISA. Pathological changes in the lung were assessed by light microscopy. Third-generation-cultured hAMSCs expressed high levels of CD29, CD44, CD49D, CD73, and CD166 levels, but low CD34 or CD45 amounts and their cytoplasm contained Vimentin. In CPB model animals, OI was elevated and RI reduced; TNF- $a$, IL-8, and MMP-9 levels were elevated, and IL-10 levels reduced within $3 \mathrm{~h}(P<0.05)$, but hAMSC transplantation significantly ameliorated these changes $(P<0.05)$. Pathological changes observed in the hAMSC group were significantly less severe than those in the CPB group. In conclusion, hAMSC transplantation can downregulate proinflammatory factors and reduce MMP-9 levels, whereas upregulating the anti-inflammatory molecule IL-10, thus reducing $\mathrm{I} / \mathrm{R}$ lung injury in a dog model of CPB.

Laboratory Investigation (2016) 96, 537-546; doi:10.1038/labinvest.2016.37; published online 29 February 2016

Cardiopulmonary bypass (CPB) is a technique used during heart surgery to maintain blood circulation and oxygenation while the heart or lungs are operated upon. The procedure involves connection of the large blood vessels to an artificial heart-lung machine using an artificial tube. Blood is withdrawn from the venous system, oxygenated outside of the body, and the oxygenated blood is then transfused back to the artery system. ${ }^{1,2}$ Complications of CPB often observed after surgery include post-perfusion syndrome, hemolysis, and decreased lung functions, which can be manifested in symptoms ranging from subclinical to acute respiratory distress syndrome (ARDS) or acute respiratory failure. Mortality following $\mathrm{CPB}$ is reported to range from 3.9 to $36.4 \%{ }^{3-5}$

$\mathrm{CPB}$-induced lung injury is thought to result from lung ischemia, reperfusion after ischemia/reperfusion (I/R) injury, and systemic inflammatory response syndrome. ${ }^{6,7}$ Blockage and recovery of circulation in the heart and lungs during $\mathrm{CPB}$ can cause endothelial damage, increase vascular permeability, and enhance recruitment or accumulation and activation of platelets and immune cells in the pulmonary circulation. ${ }^{8-11}$ Moreover, incision of the vessels and the artificial materials used in CPB can activate neutrophil granular cells, ${ }^{12}$ further causing inflammatory factors to aggregate and damaging the lung tissues. ${ }^{13}$

During $\mathrm{CPB}$, complement activation and $\mathrm{I} / \mathrm{R}$ injury can induce cytokine release, and TNF- $\alpha$, IL-1, IL-6, IL- 8 , and IL-10 have been implicated in CPB-induced lung injury. ${ }^{14}$ TNF- $\alpha$ and IL- 1 synergistically activate NF- $\kappa$ B in immune cells to cause cytokine release, inducing migration and accumulation of polymorphonuclear leukocytes (PMN), and maintaining inflammation. ${ }^{15,16}$ The inflammatory reaction

${ }^{1}$ Department of Cardiothoracic Surgery, Nanjing General Hospital of Nanjing Military Command, Nanjing, Jiangsu Province, China; ${ }^{2}$ Department of Thoracic and Cardiovascular Surgery, Affiliated Hospital of Zunyi Medical College, Zunyi, Guizhou, China and ${ }^{3}$ Key Laboratory of Cell Engineering in Guizhou Province, Affiliated Hospital of Zunyi Medical College, Zunyi, Guizhou, China

Correspondence: Dr G Liang, MD, Department of Thoracic and Cardiovascular Surgery, Affiliated Hospital of Zunyi Medical College, Zunyi, Guizhou 563003, China E-mail: guiyou515@sina.com

Received 14 August 2015; revised 6 January 2016; accepted 18 January 2016 
can directly damage vascular endothelial cells (VECs), increasing the permeability of capillaries and PMN amounts as well as the accumulation of macrophages at injury site; moreover, accumulated edema further inhibits perfusion of alveolar cells and exchange of oxygen, resulting in lung injury.

Metabolic adaptations to ischemia can induce release of reactive oxygen and nitrogen species upon reperfusion, and local and systemic immune activation involves release of protein kinases and oxidation products, including degraded metalloproteinase, elastase, and oxygen-free radicals, such as myeloperoxidase, hydrogen peroxide, and peroxide. ${ }^{17,18}$ These factors can cause oxidative damage to lung tissues, increasing alveolar endothelium permeability and infiltration of inflammatory cells, edema, impairing intrapulmonary shunt fraction and ventilation perfusion. Administration of anti-inflammatory molecules, including corticosteroids and serine protease inhibitor aprotinin, can reduce the lung damage resulting from CPB-induced I/R injury, ${ }^{19-23}$ though the molecular mechanisms underlying CPB-induced lung injury remain unclear.

Human amnion mesenchymal cells (hAMSCs) are adult stem cells that exhibit rapid proliferation in vitro, and can be differentiated into cell types derived from all three primary germ layers of the embryo in in vitro culture. ${ }^{24-26}$ hAMSCs express low levels of HLA-A, B, and C, but not HLA-DR; hence, they exhibit low immunogenicity, and hAMSC xenografts do not induce immune rejection. ${ }^{27}$ hAMSCs can be isolated from the discarded placenta amnion tissues after birth, and their abundance, plasticity, and low immunogenicity have allowed them to be used in a range of clinical applications. MSC therapy has been reported to improve outcomes in animal models of acute lung I/R injury ${ }^{28-30}$ and renal I/R injury. ${ }^{31}$

However, the relevance of these rodent studies to the clinical use of hAMSC remains to be determined. Employing larger animal models may provide more clinically relevant data. Anatomical structures and physiological functions of dogs are more similar to those of the human, and models of surgery can be more accurately recreated in these model animals. In this study, we examined the effects of venous transplantation of hAMSCs on inflammation and lung damage in a model of I/R lung injury after CPB. Our findings provide further experimental and theoretical evidence for the role of hAMSCs in the treatment of I/R-induced lung injury after CPB.

\section{MATERIALS AND METHODS}

\section{Dissociation and Primary Culture of hAMSCs}

hAMSCs were collected from fresh placenta specimens of full-term pregnancies delivered by cesarean section. Placenta samples were donated by pregnant women or their relatives, and ethical approval of this study was obtained from the ethics committee of Affiliated Hospital of Zunyi Medical College. Patients infected with HBV, HCV, HIV, or syphilis were excluded. Under sterile conditions, blood clots were removed by rinsing with D-Hanks solution, and mucus was removed by scraping with a sterilized glass slide. The amniotic membrane was processed into small pieces, stored in $\mathrm{D}$-Hanks solution at $4^{\circ} \mathrm{C}$ and used for experiments within $2 \mathrm{~h}$. The amniotic membrane was shaken with a twofold excess of trypsin solution $(0.05 \%$ trysin- $0.02 \%$ EDTA- $2 \mathrm{Na}$, Biyuntian Company, Beijing, China) at $200 \mathrm{rpm}$ and $37^{\circ} \mathrm{C}$ for $15 \mathrm{~min}$; the supernatant was discarded, and the procedure was repeated twice with incubations of 20 and $25 \mathrm{~min}$, respectively. The resultant amniotic membrane was rinsed in D-Hanks solution two or three times, and shaken with a twofold excess of $0.75 \mathrm{mg} / \mathrm{ml}$ type 2 collagenase containing $0.075 \mathrm{mg} / \mathrm{ml}$ DNase I (Worthington, NJ, USA) for 1.5-2 h. Then, the solution was filtered through 300 steel mesh. To terminate tissue digestion, LG-DMEM (Gibco, New York, NY, USA) containing 10\% fetal bovine serum (FBS) and an equal volume of filtrate were combined, and centrifuged at $2000 \mathrm{rpm}$ for $10 \mathrm{~min}$. The supernatant was discarded and the precipitated cells were cultured in suspension in complete LG-DMEM at $2.0 \times 105 \mathrm{cells} / \mathrm{cm}^{2}$ in a $25 \mathrm{~cm}^{2}$ flask at $37^{\circ} \mathrm{C}, 5 \% \mathrm{CO}_{2}$, and saturated humidity. After $48 \mathrm{~h}$, culture medium and non-adherent cells were discarded, fresh medium was added. Cell growth was observed under an inverted phase contrast microscope (IX-71-S8F, Olympus, Japan).

\section{Subculture}

When primary culture of hAMSCs reached $70 \sim 80 \%$ confluence, the culture medium was discarded, and cells were rinsed with D-PBS (Gibco) three times. Cells were digested in $1-2 \mathrm{ml} 0.125 \%$ trypsin- $0.02 \%$ sodium EDTA at $37^{\circ} \mathrm{C}$ for $3 \mathrm{~min}$. Digestion was monitored by light microscopy, and when cells shrunk and were rounded, an equal volume of LG-DMEM containing 10\% (FBS, Gibco) was immediately added to stop digestion. Digested cells were centrifuged at $1000 \mathrm{rpm}$ for $10 \mathrm{~min}$, and the supernatant was discarded. Pelleted cells were resuspended and cultured at $37^{\circ} \mathrm{C}, 5 \% \quad \mathrm{CO}_{2}$, and saturated humidity in complete LG-DMEM containing $10 \%$ FBS, seeded at $1.0 \times 10^{5}$ cells $/ \mathrm{cm}^{2}$ in a $25 \mathrm{~cm}^{2}$ flask.

\section{Phenotype Verification}

Third generation hAMSCs were digested and collected and rinsed in D-PBS, and cell density was adjusted to $1.5 \times 10^{6}$ cells $/ \mathrm{ml}$. Cell suspension $(100 \mu \mathrm{l})$ was labeled with $10 \mu \mathrm{l}$ fluorescent-conjugated antibodies directed toward CD19, CD29, CD34, CD44, CD45, CD73, CD80, CD86, and CD166, or isotype controls (BD, NJ, USA) in the dark at room temperature for $25 \mathrm{~min}$. After rinsing in $2 \mathrm{ml}$ PBS containing $0.1 \%$ FBS, cells were centrifuged at $1000 \mathrm{rpm}$ for 5 min; supernatant was discarded, and cells were resuspended in $200 \mu \mathrm{l} 1 \%$ paraformaldehyde (PFA) and stored in the dark at $2 \sim 8^{\circ} \mathrm{C}$. Staining was detected within $24 \mathrm{~h}$ using FACS Calibur (BD), and analyzed by the Cell Quest software (BD). 


\section{Immunochemistry}

Cellular content of vimentin in third-generation hAMSCs was assessed by immunochemistry. Sections were rinsed with PBS three times, fixed in 4\% PFA for $10 \mathrm{~min}$, and rinsed again in PBS three times. $0.3 \%$ Triton-X100 was added to each slide, which were rinsed with PBS and blocked in normal goat serum blocking solution at room temperature for $30 \mathrm{~min}$. Slides were then incubated with mouse monoclonal antihuman vimentin protein antibody (Sigma, USA, 1:100) at $4{ }^{\circ} \mathrm{C}$ overnight, then rinsed three times, and incubated for 30 min with secondary antibody conjugated to HRP (PowerVision poly-HRP-Anti-Mouse IgG, ImmunoLogic) at $37^{\circ} \mathrm{C}$. After rinsing three times in PBS, 3,3'-diaminobenzidine was added for $\sim 3-5 \mathrm{~min}$, and sections stained with hematoxylin for 3 min. After rinsing with tap water and dehydration, slides were mounted, and images were acquired. Vimentin signals within the cytoplasm appeared as brown granules.

\section{Animals and Grouping}

Healthy female hybrid dogs $(n=18)$ weighting $12.6 \pm 2.5 \mathrm{~kg}$ were provided by the experimental animal center of Zunyi Medical University. Dogs were housed with free access to food and water for 1 week prior to experiments, then fasted for $8 \mathrm{~h}$ and deprived of water for $4 \mathrm{~h}$. According to the rank sum test table method, dogs were divided into three groups of six animals: the Sham, $\mathrm{CPB}$, and $\mathrm{CPB}+\mathrm{hAMSC}$ groups. Animal experiments were approved by the Ethics and Animal Care Committee of the Affiliated Hospital of Zunyi Medical College.

\section{Establishment of the CPB Model and hAMSC Transplantation}

The CPB model was established as previously described. ${ }^{32}$ Dogs were anesthetized by intraperitoneal injection of $2.5 \%$ phenobarbital $(25 \mathrm{mg} / \mathrm{kg})$ and placed in the supine position. Mechanical ventilation was established by endotracheal intubation. An incision was made at the midline of the sternum; the pleural membrane was opened and the aorta separated. A cannula was inserted through a purse-string suture made at the root of the aorta $(4 \mathrm{~mm})$, and a cannula (36 Fr) was inserted in the right auricle. Simultaneously, a cannula was inserted into the femoral vein. In the sham group, the $\mathrm{CPB}$ model was established without blockage of the aorta. In the hAMSC group, the $\mathrm{CPB}$ model was established, including blockage of the aorta for $1 \mathrm{~h} ; 15 \mathrm{~min}$ after aorta opening, $1 \mathrm{ml}$ of a single-cell suspension of hAMSCs (passage 3) in normal saline $\left(2 \times 10^{7} / \mathrm{ml}\right)$ was injected into the femoral vein. In the CPB group, the aorta was blocked for $1 \mathrm{~h}$, and $15 \mathrm{~min}$ after aorta opening, normal saline was injected in place of the hAMSC suspension. Infusion of $2 \times 10^{7}$ stem cells was recently reported to improve Crohn's fistula in a small phase I clinical trial. ${ }^{33}$

\section{Sample Collection}

For calculation of the oxygen index (OI) and respiratory index (RI), $2 \mathrm{ml}$ of arterial blood was withdrawn from each animal before surgery (T1), and at $15 \mathrm{~min}$ (T2), $1 \mathrm{~h}$ (T3), $2 \mathrm{~h}$ (T4), and $3 \mathrm{~h}$ (T5) after aorta opening. In addition, $8 \mathrm{ml}$ venous blood was withdrawn at the same time points, and plasma levels of TNF- $\alpha$, matrix metalloproteinase (MMP-9), IL-8, and IL-10 were assessed by ELISA. After T5, animals were killed, right lung tissues were dissected and pathological changes in the lungs were assessed by light microscopy.

\section{Assessment of Lung Injury}

Lung tissues were fixed in 10\% PFA, dehydrated, embedded in paraffin, and cut into $5 \mu \mathrm{m}$ sections. Xylene was used for deparaffinization, and $\mathrm{H} \& \mathrm{E}$ staining was performed. Semi-quantitative scoring of bleeding, edema, and inflammation of lung tissues was performed under high magnification $(\times 400)$, using the Mayor and Osman score standard. ${ }^{34,35}$

\section{Assessment of hAMSC Localization in Lungs}

Lung tissues were harvested and fixed in 10\% neutral buffer formalin. Immunohistochemical staining was performed as previously described. ${ }^{36,37}$ The slices were stained with mouse anti-human nuclei (Catalog No. MAB1281, Merck Millipore). Images were captured with a Nikon Eclipse FN2 microscope equipped with the MetaMorph software.

\section{Measurement of Oxygenation and RIs}

OI and RI were assessed using an automatic blood gas analyzer (ABL80, Sendx Medical, USA), according to the following formulas: $\mathrm{OI}=\mathrm{PaO}_{2} / \mathrm{FiO}_{2} ; \mathrm{RI}=\mathrm{P}(\mathrm{A}-\mathrm{a}) \mathrm{O}_{2} / \mathrm{PaO}_{2}=$ $\left\{\left[\left(\mathrm{PB}-\mathrm{PH}_{2} \mathrm{O} \times \mathrm{FiO}_{2}-\mathrm{PaCO}_{2}\right]-\mathrm{PaO}_{2}\right\} / \mathrm{PaO}_{2} . \quad \mathrm{P}(\mathrm{A}-\mathrm{a}) \mathrm{O}_{2}\right.$, alveolar-arterial gradient; $\mathrm{PB}$, atmospheric pressure; $\mathrm{PH}_{2} \mathrm{O}$, saturated vapor pressure; $\mathrm{FiO}_{2}$, inhaled oxygen concentration (\%); $\mathrm{PaCO}_{2}$, artery carbon dioxide partial pressure.

\section{ELISA}

Blood was collected in pyrogen-free and non-endogenous toxin test tubes to avoid stimulation of cells during preparation, and centrifuged at $3000 \mathrm{rpm}$ for $10 \mathrm{~min}$. Supernatant serum was collected and frozen at $-20^{\circ} \mathrm{C}$, and supernatant concentrations of TNF- $\alpha$, IL- 8 , IL-10, and MMP-9 were assessed by specific kits (Beijing North institute of Biological Technology).

\section{Statistical Analysis}

The SPSS16.0 software was used for all statistical analyzes. Quantitative data were expressed as mean \pm s.d. One-way analysis of variance and Tukey's post hoc test was employed for comparison among groups. $P<0.05$ was considered statistically significant. 


\section{RESULTS}

\section{Morphological Features of hAMSCs}

Cultured hAMSCs adhered to culture flasks after $48 \mathrm{~h}$ of primary culture. Cellular morphology ranged from polygonal to spindle-shaped, or even star-shaped (Figures 1a and c). After passage for 3-5 generations, tightly packed hAMSCs adopted a fiber-like shape, and cells grew a cell monolayer with a swirled pattern (Figures $1 \mathrm{~b}$ and $\mathrm{d}$ ).

\section{hAMSC Phenotype Verification and Vimentin Expression} Immunostaining of second-, third-, and fourth-generation hAMSCs revealed high levels of CD29, CD44, CD49D, CD73, and CD166, but low-to-no CD34 or CD45 expression (Figure 2 and Table 1). Expression levels of CD29, CD44, CD49D, CD73, and CD166 increased between passages 2 and 4. By passage 4, $80.8 \pm 13.7 \%, 86.6 \pm 4.8 \%, 93.0 \pm 2.0 \%$, $97.4 \pm 0.7 \%$, and $98.0 \pm 0.5 \%$ of hAMSCs were CD29+, $\mathrm{CD} 49 \mathrm{D}+, \mathrm{CD} 166+, \mathrm{CD} 44+$, and $\mathrm{CD} 73+$, respectively. Immunohistochemistry of third-generation hAMSCs revealed cytoplasmic vimentin (Figure 3 ).
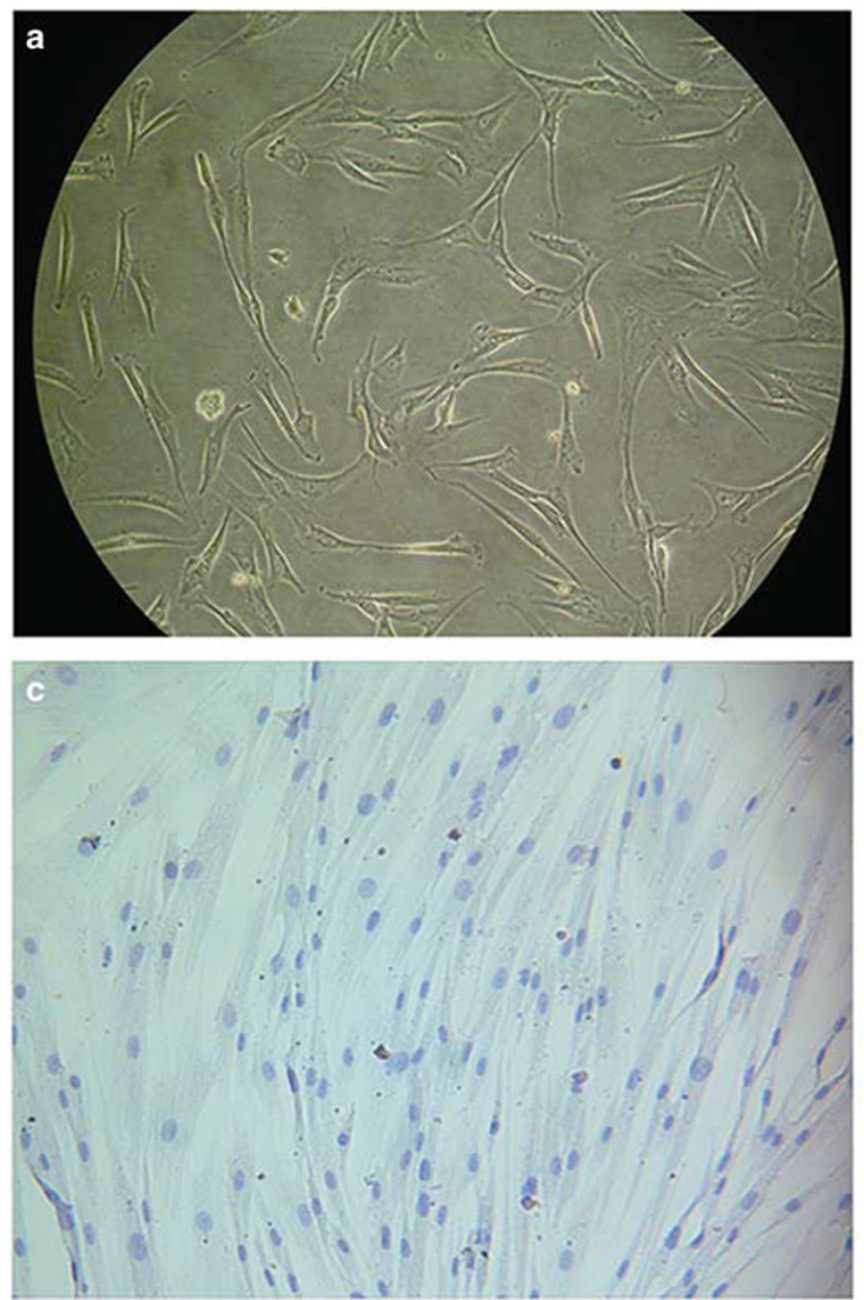

\section{hAMSC Transplantation Improves Pathology of the Damaged Lung in Dogs Subjected to CPB I/R}

A model of $\mathrm{CPB}$ was established in dogs, as previously described, ${ }^{32}$ by surgical blockage of the aorta for $1 \mathrm{~h}$. Dogs either underwent mock surgery (sham group), CPB (model group) or $\mathrm{CPB}$ followed by femoral injection of $2 \times 10^{7}$ hAMSCs (CPB+hAMSC group). In comparison with the sham group, alveolar septum in the model group was significantly widened, and dilation and congestion of the capillaries, leakage of red blood cells, and infiltration of neutrophil granular cells were observed in the lung interstitial tissue (Figures $3 \mathrm{~d}$ and $\mathrm{f}$ ). In the hAMSC group, these pathological changes were markedly less severe than those observed in the model group, and reduced leakage of red blood cells, infiltration of neutrophil granular cells, and dilation and congestion of capillaries were observed in the lung interstitial tissue (Figure 3).

Lung injury index did not differ significantly between the three groups before $\mathrm{CPB}(P>0.05)$. However, lung injury indexes of the $\mathrm{CPB}$ and $\mathrm{CPB}+\mathrm{hAMSC}$ groups were
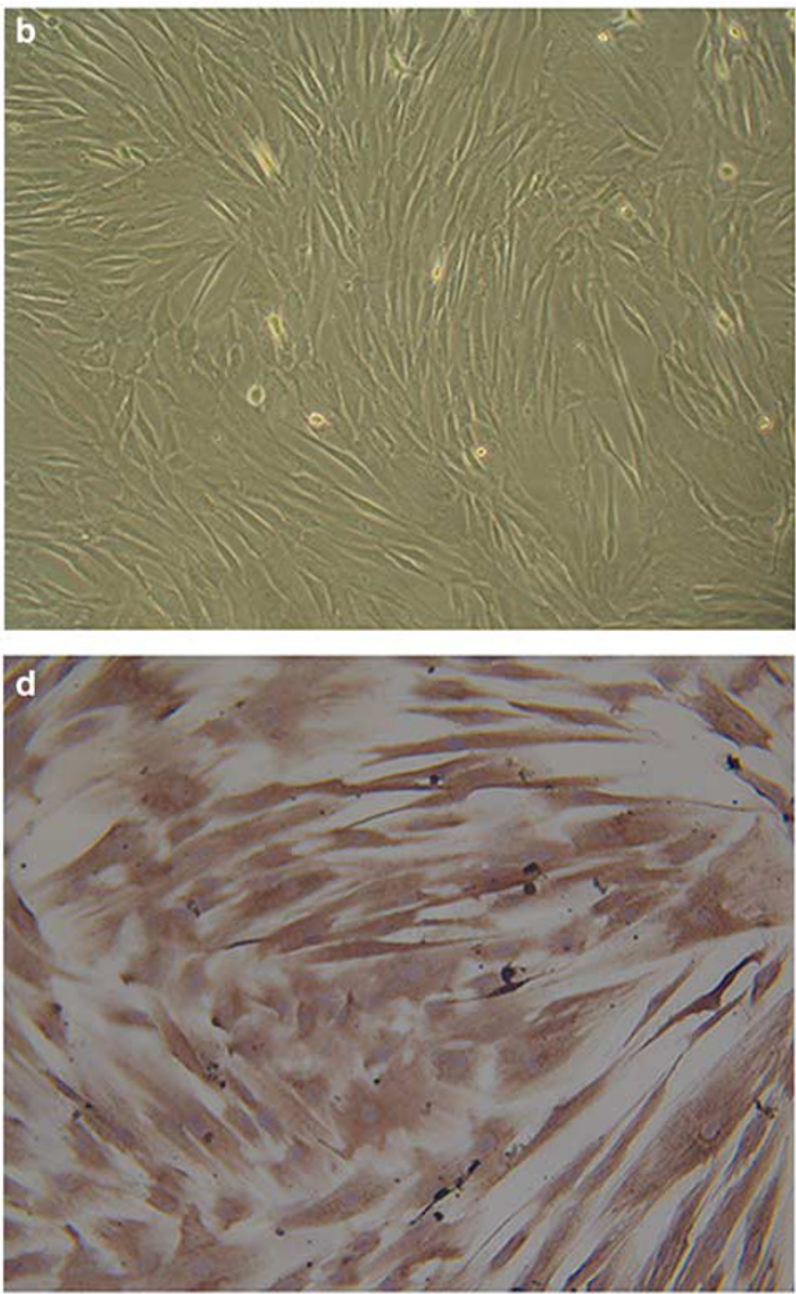

Figure 1 Morphology of primary hAMSCs (a) and 3rd passage hAMSCs (b) cultured ex vivo (×200). (c-d) Vimentin expression in third-generation hAMSCs was assessed by immunochemistry $(\times 200)$. 

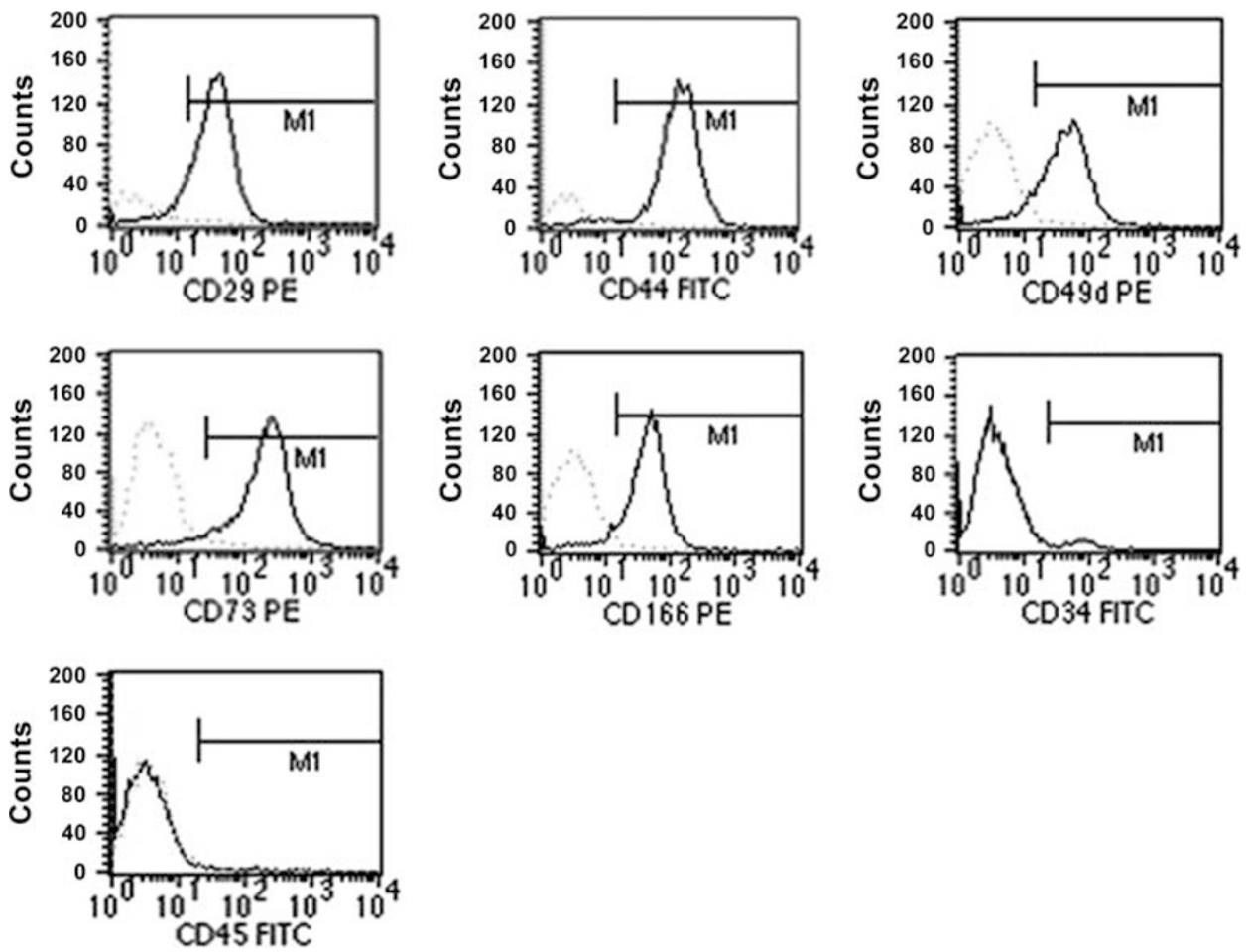

Figure 2 Cell surface markers of third-generation hAMSCs were assessed by immunostaining, detected by flow cytometry. Green line indicates isotype control, and black line indicates cell surface marker antibody.

Table 1 Cultured hAMSC cell surface markers $(n=3-7, \bar{x} \pm s)$

\begin{tabular}{lccc}
\hline Cell surface marker & \multicolumn{3}{c}{ Positively stained cells (\%) } \\
\cline { 2 - 4 } & Passage 2 & Passage 3 & Passage 4 \\
\hline CD29 & $60.1 \pm 11.4$ & $84.8 \pm 17.4$ & $80.8 \pm 13.7$ \\
CD44 & $69.9 \pm 16.0$ & $92.5 \pm 4.0$ & $97.4 \pm 0.7$ \\
CD49d & $33.4 \pm 35.0$ & $74.2 \pm 7.7$ & $86.6 \pm 4.8$ \\
CD73 & $73.6 \pm 18.8$ & $96.41 \pm 1.8$ & $98.0 \pm 0.5$ \\
CD166 & $82.3 \pm 15.3$ & $89.8 \pm 5.4$ & $93.0 \pm 2.0$ \\
CD34 & $1.3 \pm 0.7$ & 0 & 0 \\
CD45 & $0.16 \pm 0.12$ & 0 & 0 \\
\hline
\end{tabular}

Compared to the sham group, ${ }^{\mathrm{a}} P<0.05,{ }^{\mathrm{b}} P<0.01$. Compared to the $\mathrm{CPB}$ group, ${ }^{C} P<0.05,{ }^{d} P<0.01$. Compared to the results at $\mathrm{T} 1$ in the same group, ${ }^{\mathrm{e}} P<0.05,{ }^{\mathrm{f}} P<0.01$.

significantly higher than that of the sham group 1,2 , and $3 \mathrm{~h}$ after aorta opening $(P<0.05, P<0.01$, and $P<0.01$, respectively). Interestingly, lung injury indexes in the $\mathrm{CPB}+\mathrm{hAMSC}$ group were significantly lower than the values obtained for the $\mathrm{CPB}$ group, 1,2 , and $3 \mathrm{~h}$ after hAMSC transplantation $(P<0.05, P<0.01$, and $P<0.01$, respectively) (Figure $3 \mathrm{~g}$ and Table 2).
Compared with the sham group, ${ }^{\mathrm{a}} P<0.05,{ }^{\mathrm{b}} P<0.01$. Compared with the $\mathrm{CPB}$ group, ${ }^{\mathrm{c}} P<0.05,{ }^{\mathrm{d}} P<0.01$. Compared with the results at $\mathrm{T} 1$ in the same group, ${ }^{\mathrm{e}} \mathrm{P}<0.05,{ }^{\mathrm{f}} \mathrm{P}<0.01$ before surgery (T1), and at $15 \mathrm{~min}$ (T2), $1 \mathrm{~h}$ (T3), $2 \mathrm{~h}$ (T4), and $3 \mathrm{~h}$ (T5) after aorta opening.

\section{hAMSC Transplantation Improves OI and RI in Dogs with CPB-induced I/R Injury}

In model animals, OI values were significantly reduced $15 \mathrm{~min}, 1 \mathrm{~h}, 2 \mathrm{~h}$, and $3 \mathrm{~h}$ after aorta opening $(P<0.01)$. Interestingly, OI values were significantly higher in the hAMSC group compared with model group animals at 2 and $3 \mathrm{~h}$ after hAMSC transplantation $(P<0.05$ and $P<0.01$, respectively; Figure 4a). RI values were significantly increased in model animals at 2 and $3 \mathrm{~h}$ after aorta opening $(P<0.05$ and $P<0.01$, respectively), but the RI values were significantly lower in hAMSC group animals than the model group at 1,2 , and $3 \mathrm{~h}$ after hAMSC transplantation $(P<0.05, P<0.01$, and $P<0.01$, respectively; Figure 4b).

\section{hAMSCs Alleviate Expression of Proinflammatory Factors but Induce Anti-Inflammatory Factors in Dogs Subjected to CPB-Induced I/R Injury}

Circulating levels of TNF- $\alpha$ and IL- 8 were higher in model animals than in the sham group at $15 \mathrm{~min}, 1 \mathrm{~h}, 2 \mathrm{~h}$, and $3 \mathrm{~h}$ after aorta opening $(P<0.05$ or $P<0.01$; Figures $5 \mathrm{a}$ and $\mathrm{b})$. 

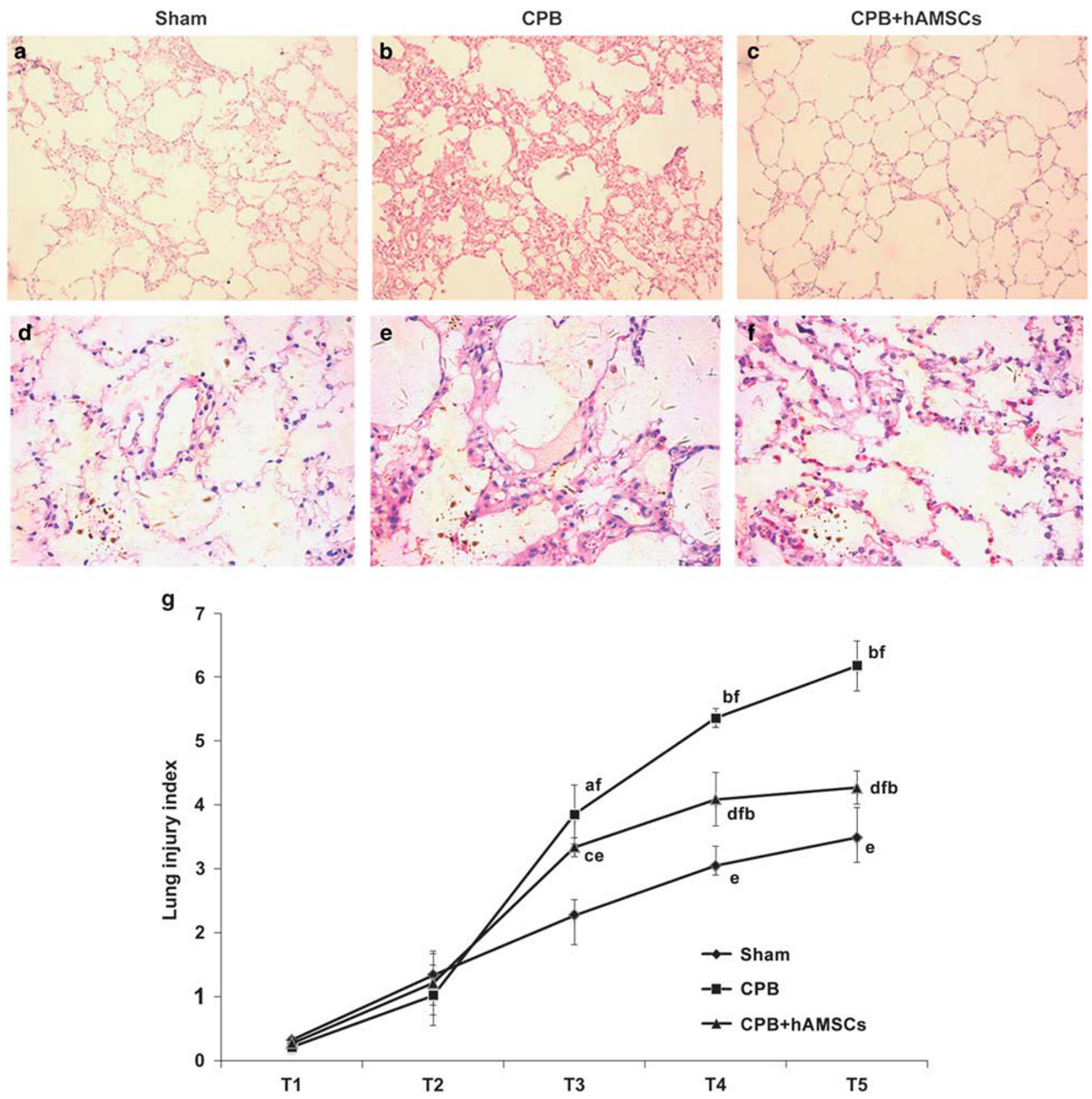

Figure 3 Effect of hAMSC transplantation on pathological changes in the lung $3 \mathrm{~h}$ after cardiopulmonary bypass-induced I/R injury in dogs (a-f). (a-c) $\times 200$; $(\mathbf{d}-\mathbf{f}) \times 400$. $(\mathbf{g})$ Quantification of lung injury score from H\&E-staining results.

Table 2 Comparison of lung injury index in different time point (mean \pm s.d.)

\begin{tabular}{llllll}
\hline Group & $T_{1}$ & $T_{2}$ & $T_{3}$ & $T_{4}$ & $T_{5}$ \\
\hline Sham & $0.32 \pm 0.05$ & $1.34 \pm 0.33$ & $2.27 \pm 0.25$ & $3.05 \pm 0.30^{e}$ & $3.49 \pm 0.477^{e}$ \\
CPB & $0.21 \pm 0.033$ & $1.02 \pm 0.47$ & $3.85 \pm 0.46^{\mathrm{a}, f}$ & $5.36 \pm 0.15^{\mathrm{b}, \mathrm{f}}$ & $6.18 \pm 0.39^{\mathrm{b}, f}$ \\
CPB+hAMSCS & $0.27 \pm 0.08$ & $1.21 \pm 0.50$ & $3.34 \pm 0.15^{\mathrm{c}, \mathrm{e}}$ & $4.09 \pm 0.42^{\mathrm{d}, \mathrm{f}, \mathrm{b}}$ & $4.27 \pm 0.26$
\end{tabular}

Serum IL-10 levels were lower in model group animals than the sham group 15 min after $\mathrm{CPB}$-induced I/R injury, and decreased further at 1,2 , and $3 \mathrm{~h}(P<0.05$ or $P<0.01)$. However, these changes were somewhat ameliorated in hAMSC group animals at 1,2 , and $3 \mathrm{~h}(P<0.05, P<0.01$, and $P<0.01$, respectively; Figure 5c).

Circulating levels of MMP-9 were higher in model animals than in the sham group at $15 \mathrm{~min}, 1 \mathrm{~h}$, and $2 \mathrm{~h}$ after aorta opening $(P<0.05$ or $P<0.01)$, peaking at $15 \mathrm{~min}$. However, 

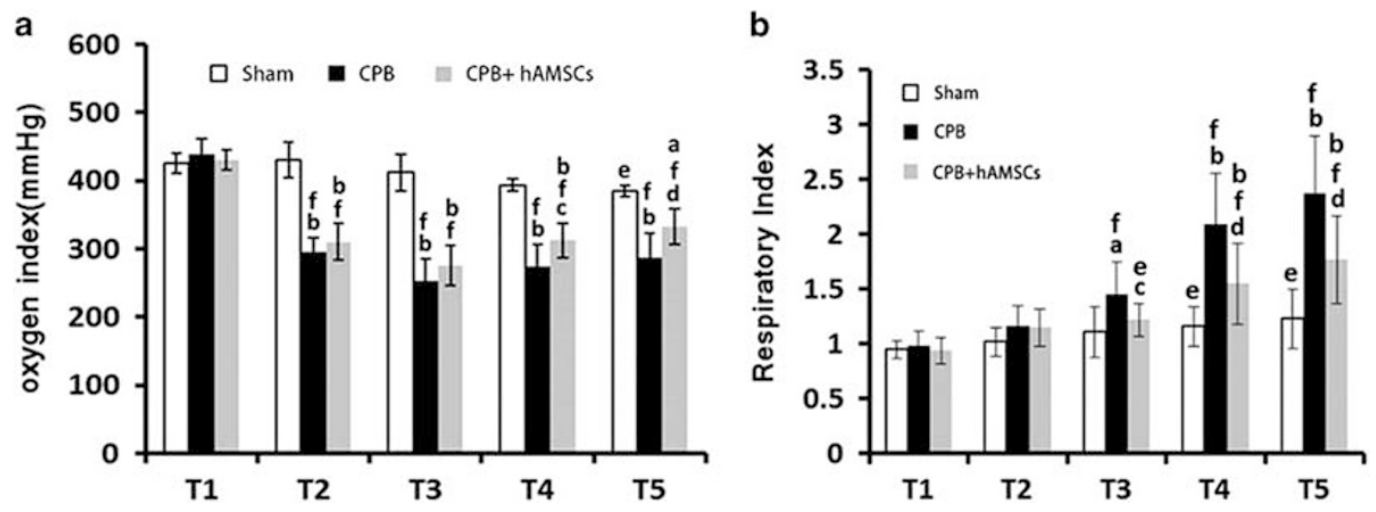

Figure 4 Effect of hAMSC transplantation on OI (a) and RI (b) values in dogs with cardiopulmonary bypass-induced I/R injury. Compared with the sham group: ${ }^{\mathrm{a}} P<0.05,{ }^{\mathrm{b}} P<0.01$; compared with the model group ${ }^{\mathrm{C}} P<0.05$, ${ }^{\mathrm{d}} P<0.01$; compared with $\mathrm{T} 1$ within the same group: ${ }^{\mathrm{e}} P<0.05$, ${ }^{\mathrm{f}} P<0.01$ For calculation of oxygen index (OI) and respiratory index (Rl), $2 \mathrm{ml}$ of arterial blood was withdrawn from each animal before surgery (T1), and at 15 min (T2), $1 \mathrm{~h} \mathrm{~T}$ ), $2 \mathrm{~h}$ (T4) and $3 \mathrm{~h}$ after aorta opening (T5).

a

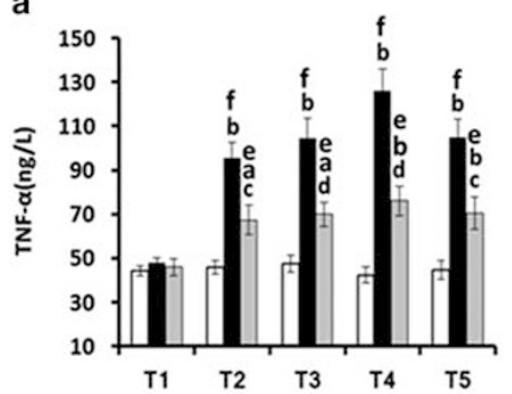

C

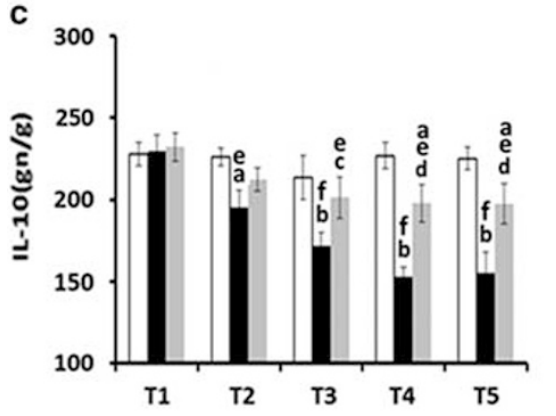

b

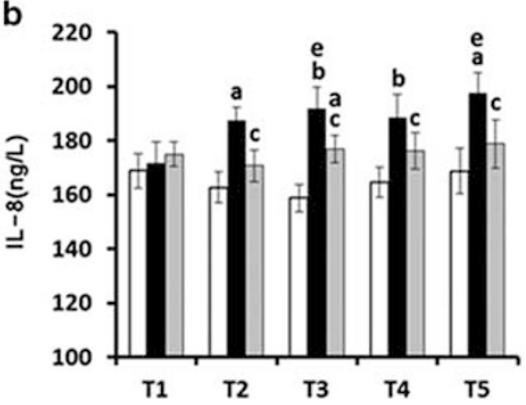

d

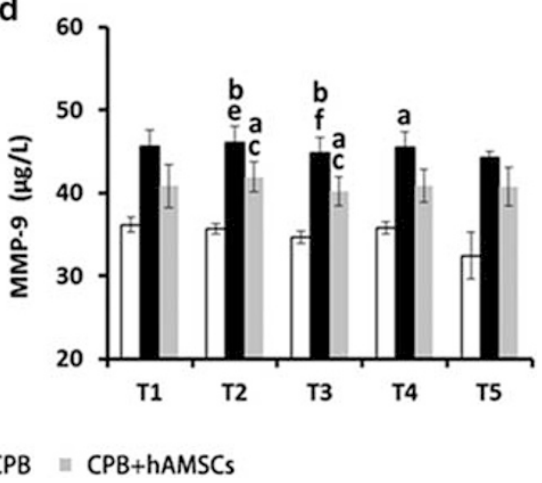

Figure 5 Effect of hAMSC transplantation on TNF- $a(\mathbf{a})$, IL-8 (b), IL-10 (c), and MMP-9 (d) levels in dogs with cardiopulmonary bypass-induced I/R injury. Compared with the sham group: ${ }^{a} P<0.05,{ }^{b} P<0.01$; compared with the model group: ${ }^{c} P<0.05,{ }^{d} P<0.01$; compared with the T1 within the same group: ${ }^{\mathrm{e}} P<0.05,{ }^{\mathrm{f}} P<0.01$ before surgery (T1), and at $\left.15 \mathrm{~min}(\mathrm{~T} 2), 1 \mathrm{~h} \mathrm{T3}\right), 2 \mathrm{~h}$ (T4), and $3 \mathrm{~h}$ after aorta opening (T5).

there was no significant difference in circulating levels of MMP-9 between model and naive animals after $3 \mathrm{~h}$ $(P>0.05)$. Circulating levels of MMP-9 were significantly lower in the hAMSC group than the model group $15 \mathrm{~min}$ and $1 \mathrm{~h}$ after hAMSC transplantation $(P<0.05)$; however, no statistically significant differences were observed at later time points $(P>0.05$; Figure $5 \mathrm{~d})$.

\section{Human Nuclei Immunostaining Reveals Localization of hAMSCs in the Lung}

In order to confirm the localization of hAMSCs after transplantation in dogs, we used human nuclei antibody to stain the lung tissues from sham (negative control) and CPB+hAMSC group animals $3 \mathrm{~h}$ after hAMSC transplantation. We detected abundant human nuclei-positive hAMSCs in lung 

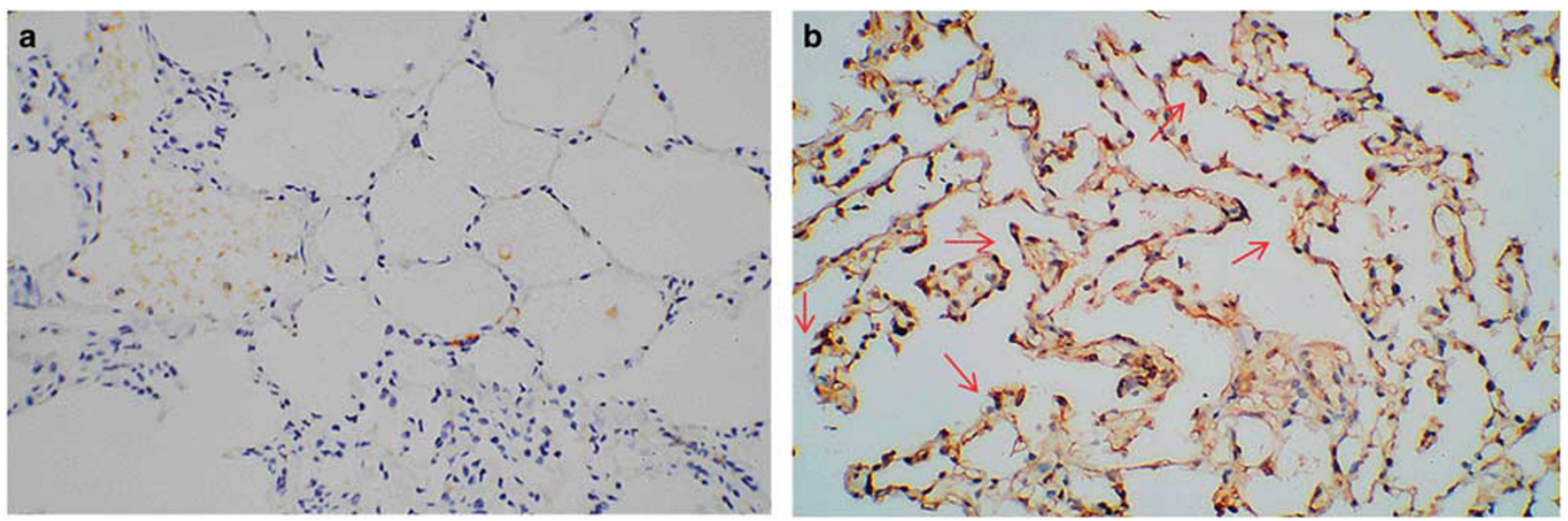

Figure 6 Human nuclei immunostaining reveals localization of hAMSCs in the lung. Immunohistological analysis of lung sections stained with human nuclei from lung tissues of sham and CPB+hAMSC group dogs $3 \mathrm{~h}$ after hAMSC transplantation. (a) Sham group (negative control). (b) CPB+hAMSC group (red arrow indicates human nuclei-positive hAMSC cells) $(\times 200)$.

tissues from $\mathrm{CPB}+\mathrm{hAMSC}$ animals $3 \mathrm{~h}$ after injection of hAMSC into the femoral vein (indicated by red arrows in Figure $6 \mathrm{~b}$ ); however, no human nuclei staining signals were observed in sham group lung tissues (Figure 6a). These results indicated that the transplanted hAMSCs were recruited to injured regions of the lung after $\mathrm{CPB}$.

\section{DISCUSSION}

In this study, we examined the effects of venous transplantation of hAMSCs on inflammation and lung damage in a model of $\mathrm{I} / \mathrm{R}$ lung injury after $\mathrm{CPB}$. hAMSCs were isolated from human amniotic membrane by enzymatic digestion, and primary and passaged hAMSCs were cultured ex vivo. Cultured hAMSCs were adherent and expressed MSCs markers (CD29, CD44, CD49D, CD73, and CD166) and cytoplasmic vimentin. These cultured hAMSCs thus met the standard criteria of the International Society for Cellular Therapy for MSCs.

We transplanted these highly purified hAMSCs into dogs after $\mathrm{CPB}$ establishment, and examined the effect of this therapy on I/R lung injury. The hAMSCs appeared to localize to the lungs, as indicated by human nuclei staining, within $3 \mathrm{~h}$ of injection into the femoral vein. These findings are consistent with previous reports. ${ }^{38-40}$ In agreement, intratracheal transplantation of hAMSCs was reported to efficiently attenuate lung injury in a rat model of hyperoxic lung injury in newborn rats. ${ }^{39}$

As cytokines are the main endogenous mediators of $I / R$ injury, we measured circulating levels of the proinflammatory cytokines TNF- $\alpha$ and IL- 8 in these animals. TNF- $\alpha$ is released during inflammation and mediates tissue injury by enhancing the activity of mononuclear cells and macrophages, and increasing the expression of cell adhesive factors. IL- 8 induces accumulation of white blood cells in inflammatory tissues. In contrast, IL-10 inhibits transcription of proinflammatory cytokines, such as TNF- $\alpha$, IL-1, IL-6, and IL-8, and intercellular adhesion molecule 1 , and reduces white blood cell adhesion to VECs in the lung, consequently reducing I/R lung injury. Karlsson et al. ${ }^{41}$ demonstrated that hAMSCs mediate immuno-regulatory effects through cytokine secretion. In this study, serum levels of the proinflammatory cytokines TNF- $\alpha$ and IL- 8 were significantly increased during $\mathrm{CPB}$ and $15 \mathrm{~min}$, $1 \mathrm{~h}, 2 \mathrm{~h}$, and $3 \mathrm{~h}$ after I/R injury, whereas serum levels of IL-10 started to decrease 15 min after CPB-induced I/R injury, and dropped further in the following $3 \mathrm{~h}$. These findings indicate that $\mathrm{CPB}$ and $\mathrm{I} / \mathrm{R}$ injury disrupt the normal balance between these cytokines, initiating an early inflammatory reaction and inducing PMN accumulation, and consequently inducing lung tissue damage. Venous transplantation of hAMSCs significantly reduced serum levels of TNF- $\alpha$ and IL-8 at $15 \mathrm{~min}, 1 \mathrm{~h}, 2 \mathrm{~h}$, and $3 \mathrm{~h}$ after $\mathrm{I} / \mathrm{R}$ injury, and markedly increased serum levels of IL-10. These results indicate that venous transplantation of hAMSCs reduces the release of proinflammatory factors in response to injury, alleviating inflammation in the damaged lung.

MMPs are endogenous proteinases that can lyse many extracellular matrix proteins such as collagen, elastin, and glucosamine. MMP-9 is mainly derived from inflammatory cells such as PMN, mononuclear phagocytes, and lymphocytes; it is released as plasminogen and activated through the proteolysis cascade. ${ }^{42-45}$ MMP-9 can degrade alveolar capillary basement membrane, increasing capillary permeability, leading to acute lung injury, or even ARDS. ${ }^{46}$ In this study, we found that MMP-9 levels were significantly increased $15 \mathrm{~min}, 1 \mathrm{~h}$, and $2 \mathrm{~h}$ after I/R injury, peaking at 15 min after aorta opening, but no significant difference was observed in the following $3 \mathrm{~h}$. Eichler et al. ${ }^{47}$ reported a positive correlation between the MMP-9 level in the bronchoalveolar lavage fluid and increased post-surgery alveolar-arterial gradient in pigs subjected to $\mathrm{CPB}$, and it is believed that high MMP levels in the lung are associated with the development of ALI after CPB. In this study assessing immediate venous hAMSC transplantation after CPB-induced 
I/R injury, we demonstrated that hAMSCs could reduce MMP-9 levels during the early phase of CPB. These observations suggest that hAMSCs reduce capillary permeability, and thus intrapulmonary shunt and hypoxia through inhibition of MMP-9, reducing CPB-induced I/R injury. Owing to hAMSC localization to the lung, these effects may be mediated by a paracrine mechanism.

In summary, venous transplantation of hAMSCs can significantly alleviate lung injury induced by $\mathrm{I} / \mathrm{R}$ after $\mathrm{CPB}$ in dogs. The therapeutic effects of hAMSCs are associated with downregulation of the proinflammatory factors TNF- $\alpha$ and IL-8, reduced MMP-9 levels, and upregulation of the anti-inflammatory factor IL-10. Although our study demonstrated the treatment value and significance of hAMSCs in $\mathrm{CPB}$-induced $\mathrm{I} / \mathrm{R}$ injury, the mechanisms underlying lung injury induced by $\mathrm{CPB}$ and $\mathrm{I} / \mathrm{R}$ injury are very complex, and the regulatory networks involved need to be further investigated.

\section{ACKNOWLEDGMENTS}

This work was supported by the Science and Technology Research Key Project of Guizhou Province (No. 2014-3022) and the Science and Technology Research Key Project of Zunyi City (No. 2013-38).

\section{DISCLOSURE/CONFLICT OF INTEREST}

The authors declare no conflict of interest.

1. Sevuk U, Cakil N, Altindag $\mathrm{R}$ et al. Relationship between nadir hematocrit during cardiopulmonary bypass and postoperative hyperglycemia in nondiabetic patients. Heart Surg Forum 2014;17: E302-E307.

2. Engels $M$, Bilgic $E$, Pinto $A$ et al. A cardiopulmonary bypass with deep hypothermic circulatory arrest rat model for the investigation of the systemic inflammation response and induced organ damage. J Inflamm (Lond) 2014;11:26.

3. Ranucci M, Isgro G, Carlucci $C$ et al. Central venous oxygen saturation and blood lactate levels during cardiopulmonary bypass are associated with outcome after pediatric cardiac surgery. Crit Care 2010;14:R149.

4. Chen $\mathrm{H}$, Cheng ZB, Yu RG. Procalcitonin as a predictor of moderate to severe acute respiratory distress syndrome after cardiac surgery with cardiopulmonary bypass: a study protocol for a prospective cohort study. BMJ Open 2014;4:e006344.

5. Nakamura $\mathrm{H}$, Yamaguchi $\mathrm{H}$, Amano $\mathrm{A}$ et al. Venovenous extracorporeal membrane oxygenation is effective against post-cardiotomy acute respiratory failure in adults. Gen Thorac Cardiovasc Surg 2013;61: 402-408.

6. Cheng C, Li S, Wang $Y$ et al. Ischemic postconditioning alleviates lung injury and maintains a better expression of aquaporin-1 during cardiopulmonary bypass. Chin Med J (Engl) 2014;127:4012-4018.

7. Dolkart O, Amar E, Shapira S et al. Temporal determination of lung NO system and COX-2 upregulation following ischemia-reperfusion injury. Exp Lung Res 2014:40:22-29.

8. Shigematsu T, Wolf RE, Granger DN. T-lymphocytes modulate the microvascular and inflammatory responses to intestinal ischemiareperfusion. Microcirculation 2002;9:99-109.

9. Burne-Taney MJ, Ascon DB, Daniels F et al. B cell deficiency confers protection from renal ischemia reperfusion injury. J Immunol 2003;171: 3210-3215.

10. Day YJ, Huang $\mathrm{L}, \mathrm{Ye} \mathrm{H}$ et al. Renal ischemia-reperfusion injury and adenosine $2 \mathrm{~A}$ receptor-mediated tissue protection: the role of $\mathrm{CD} 4+$ T cells and IFN-gamma. J Immunol 2006;176:3108-3114.

11. de Vries DK, Lindeman JH, Ringers $J$ et al. Donor brain death predisposes human kidney grafts to a proinflammatory reaction after transplantation. Am J Transplant 2011;11:1064-1070.
12. Gu YJ, Boonstra PW, Graaff R et al. Pressure drop, shear stress, and activation of leukocytes during cardiopulmonary bypass: a comparison between hollow fiber and flat sheet membrane oxygenators. Artif Organs 2000;24:43-48.

13. Banz $Y$, Rieben $R$, Zobrist $C$ et al. Addition of dextran sulfate to blood cardioplegia attenuates reperfusion injury in a porcine model of cardiopulmonary bypass. Eur J Cardiothorac Surg 2008;34:653-660.

14. Halter J, Steinberg J, Fink $\mathrm{G}$ et al. Evidence of systemic cytokine release in patients undergoing cardiopulmonary bypass. J Extra Corpor Technol 2005:37:272-277.

15. Zhou E, Li Y, Wei Z et al. Schisantherin A protects lipopolysaccharideinduced acute respiratory distress syndrome in mice through inhibiting NF-kappaB and MAPKs signaling pathways. Int Immunopharmacol 2014:22:133-140.

16. Shembade N, Harhaj NS, Liebl DJ et al. Essential role for TAX1BP1 in the termination of TNF-alpha-, IL-1- and LPS-mediated NF-kappaB and JNK signaling. EMBO J 2007;26:3910-3922.

17. Esme $\mathrm{H}$, Fidan $\mathrm{H}$, Koken $\mathrm{T}$ et al. Effect of lung ischemia-reperfusion on oxidative stress parameters of remote tissues. Eur J Cardiothorac Surg 2006;29:294-298.

18. McMillen MA, Huribal M, Sumpio B. Common pathway of endothelialleukocyte interaction in shock, ischemia, and reperfusion. Am J Surg 1993;166:557-562.

19. Liakopoulos OJ, Schmitto JD, Kazmaier $\mathrm{S}$ et al. Cardiopulmonary and systemic effects of methylprednisolone in patients undergoing cardiac surgery. Ann Thorac Surg 2007:84:110-118; discussion 118-119.

20. Warren O, Darzi A, Athanasiou T. What is the role of leukocyte depletion in cardiac surgery? Heart Lung Circ 2007;16:398-399; author reply 399-400.

21. Eisses MJ, Velan T, Aldea GS et al. Strategies to reduce hemostatic activation during cardiopulmonary bypass. Thromb Res 2006;117: 689-703.

22. Williams GD, Ramamoorthy C, Chu L et al. Modified and conventional ultrafiltration during pediatric cardiac surgery: clinical outcomes compared. J Thorac Cardiovasc Surg 2006;132:1291-1298.

23. Manuelpillai U, Moodley $\mathrm{Y}$, Borlongan CV et al. Amniotic membrane and amniotic cells: potential therapeutic tools to combat tissue inflammation and fibrosis? Placenta 2011:32(Suppl 4):S320-S325.

24. Chang CJ, Yen ML, Chen YC et al. Placenta-derived multipotent cells exhibit immunosuppressive properties that are enhanced in the presence of interferon-gamma. Stem Cells 2006;24:2466-2477.

25. Banas RA, Trumpower C, Bentlejewski $C$ et al. Immunogenicity and immunomodulatory effects of amnion-derived multipotent progenitor cells. Hum Immunol 2008;69:321-328.

26. Dominici $M$, Le Blanc $K$, Mueller I et al. Minimal criteria for defining multipotent mesenchymal stromal cells. The International Society for Cellular Therapy position statement. Cytotherapy 2006;8:315-317.

27. Bailo $M$, Soncini $M$, Vertua $E$ et al. Engraftment potential of human amnion and chorion cells derived from term placenta. Transplantation 2004;78:1439-1448.

28. Yip HK, Chang YC, Wallace CG et al. Melatonin treatment improves adipose-derived mesenchymal stem cell therapy for acute lung ischemia-reperfusion injury. J Pineal Res 2013;54:207-221.

29. Liu K, Chen HL, Huang $\mathrm{H}$ et al. Curcumin attenuates cardiopulmonary bypass-induced lung oxidative damage in rats. J Cardiovasc Pharmacol Ther 2012;17:395-402.

30. Gao W, Zhao J, Kim $\mathrm{H}$ et al. alpha1-Antitrypsin inhibits ischemia reperfusion-induced lung injury by reducing inflammatory response and cell death. J Heart Lung Transplant 2014;33:309-315.

31. de Vries DK, Schaapherder AF, Reinders ME. Mesenchymal stromal cells in renal ischemia/reperfusion injury. Front Immunol 2012;3:162.

32. Liang GY, Cai QY, Niu YM et al. Cardiac glucose uptake and suppressed expression/translocation of myocardium glucose transport-4 in dogs undergoing ischemia-reperfusion. Exp Biol Med (Maywood) 2008;233: 1142-1148.

33. Cho YB, Lee WY, Park KJ et al. Autologous adipose tissue-derived stem cells for the treatment of Crohn's fistula: a phase I clinical study. Cell Transplant 2013;22:279-285.

34. Mayer J, Laine VJ, Rau B et al. Systemic lymphocyte activation modulates the severity of diet-induced acute pancreatitis in mice. Pancreas 1999;19:62-68. 
35. Osman MO, Kristensen JU, Jacobsen $\mathrm{NO}$ et al. A monoclonal antiinterleukin 8 antibody(WS-4) inhibits cytokine response and acute necrotising pancreatitis in rabbits. Gut 1998;43:232-239.

36. Xu X, Yavar Z, Verdin M et al. Effect of early particulate air pollution exposure on obesity in mice: role of p47phox. Arterioscler Thromb Vasc Biol 2010;3:2518-2527.

37. Xu X, Ying Z, Cai M et al. Exercise ameliorates high-fat diet-induced metabolic and vascular dysfunction, and increases adipocyte progenitor cell population in brown adipose tissue. Am J Physiol Regul Integr Comp Physiol 2011;300:R1115-R1125.

38. Sung DK, Chang YS, Ahn SY et al. Optimal route for human umbilical cord blood-derived mesenchymal stem cell transplantation to protect against neonatal hyperoxic lung injury: gene expression profiles and histopathology. PloS One 2015;10:e0135574.

39. Mouiseddine M, Francois S, Semont A et al. Human mesenchymal stem cells home specifically to radiation-injured tissues in a non-obese diabetes/severe combined immunodeficiency mouse model. $\mathrm{Br} J$ Radiol 2007;80:S49-S55.

40. Rojas M, Gupta N, Majka SM. Mesenchymal Stem Cells: Complex Players in Lung Repair and Injury[M]//Stem Cells and Cancer Stem Cells, Volume 7. Springer: the Netherlands, 2012, pp 145-154.

41. Karlsson H, Samarasinghe S, Ball LM et al. Mesenchymal stem cells exert differential effects on alloantigen and virus-specific T-cell responses. Blood 2008;112:532-541.
42. Fares RC, Gomes Jde A, Garzoni LR et al. Matrix metalloproteinases 2 and 9 are differentially expressed in patients with indeterminate and cardiac clinical forms of Chagas disease. Infect Immun 2013;81: 3600-3608.

43. Valimaki J, Uusitalo H. Matrix metalloproteinases (MMP-1, MMP-2, MMP-3 and MMP-9, and TIMP-1, TIMP-2 and TIMP-3) and markers for vascularization in functioning and non-functioning bleb capsules of glaucoma drainage implants. Acta Ophthalmol 2015;93: 450-456.

44. Toufaily C, Charfi C, Annabi B et al. A role for the cavin-3/matrix metalloproteinase- 9 signaling axis in the regulation of PMA-activated human HT1080 fibrosarcoma cell neoplastic phenotype. Cancer Growth Metastasis 2014;7:43-51.

45. Petrovska-Cvetkovska D, Dolnenec-Baneva N, Nikodijevik D et al. Correlative study between serum matrix metalloproteinase 9 values and neurologic deficit in acute, primary, supratentorial, intracerebral haemorrhage. Prilozi 2014;35:39-44.

46. Wang C, Li D, Qian $Y$ et al. Increased matrix metalloproteinase-9 activity and mRNA expression in lung injury following cardiopulmonary bypass. Lab Invest 2012;92:910-916.

47. Eichler W, Bechtel JF, Schumacher J et al. A rise of MMP-2 and MMP-9 in bronchoalveolar lavage fluid is associated with acute lung injury after cardiopulmonary bypass in a swine model. Perfusion 2003;18: 107-113. 